\title{
Effect of the COVID-19 pandemic and social distancing measures on the sexual functions of women treated for vaginismus (genitopelvic pain/penetration disorder)
}

\author{
Funda Gungor Ugurlucan ${ }^{1} \cdot$ Cenk Yasa $^{1}$ - Muge Ates Tikiz ${ }^{1} \cdot$ Ipek Evruke $^{1} \cdot$ Cansu Isik $^{2} \cdot$ Ozlem Dural $^{1}$. \\ Suleyman Engin Akhan ${ }^{1}$
}

Received: 29 October 2020 / Accepted: 28 December 2020 / Published online: 19 February 2021

(C) The International Urogynecological Association 2021

\begin{abstract}
Introduction and hypothesis Female sexual function is influenced by the emotional and hormonal state. COVID-19 has been the major global health crisis of our time with high psychosocial impact. Vaginismus is a form of female sexual dysfunction and a subset of genitopelvic pain/penetration disorder in which any form of vaginal penetration is painful or impossible. Our aim was to evaluate the effect of the COVID-19 pandemic on sexual function of women treated for vaginismus.

Materials and methods All women treated using dilators between 2018-2019 were included. Data obtained 3 months after comfortable penetration and during the pandemic via telephone interview were compared. The Female Sexual Function Index (FSFI), Golombok-Rust Inventory of Sexual Satisfaction (GRISS), and Beck Depression Inventory (BDI) were used to evaluate sexual function and depression. Frequency of sexual intercourse and pain was compared using a visual analogue scale.

Results Seventy-seven women were included. Mean duration of treatment and number of treatment sessions were $3.5 \pm 2.6$ months and 4.2 \pm 2.6 , respectively. There were significant improvements in the FSFI desire, arousal, orgasm, and pain subscales and total score and in the GRISS infrequency, noncommunication, avoidance, non-sensuality, and vaginismus subscales and total score during the pandemic. The GRISS dissatisfaction and anorgasmia subscales and BDI score significantly worsened. Mean frequency of sexual intercourse was $2.3 \pm 1.8$ /week and did not change significantly. Pain scores decreased during the pandemic $(2.7 \pm 2.8)$ compared to post-treatment $(6.2 \pm 2.9)$.

Conclusion Although frequency of sexual intercourse was not affected and pain scores and FSFI total and subscale scores improved, satisfaction and orgasm were adversely affected, which may be attributed to increased stress and anxiety during the pandemic.
\end{abstract}

Keywords Coronavirus · COVID-19 · Female Sexual Function Index (FSFI) - Sexual behavior · Genitopelvic pain/penetration disorder · Vaginismus

\section{Introduction}

The World Health Organization (WHO) declared coronavirus disease 2019 (COVID-19) caused by SARS-CoV-2 a pandemic, and many countries including Turkey have taken strict

Funda Gungor Ugurlucan

fgungor@yahoo.com

1 Department of Obstetrics and Gynecology, Istanbul University, Istanbul Faculty of Medicine, Capa, 34093 Istanbul, Turkey

2 Department of Midwifery, University of Health Sciences, Hamidiye Faculty of Health Sciences, Istanbul, Turkey protective measures such as border closures, transportation restrictions, lock-downs, and quarantines [1]. The disease was confirmed to have reached Turkey on 11 March 2020, and by April 12020 it was confirmed that COVID-19 had spread all over Turkey [2]. As of November 22, 2020, the total number of confirmed cases in the country was $>486,822$, and among these cases, 374,637 patients have recovered and 12,358 have died [3]. The COVID-19 pandemic has been the major global health crisis of our time and has been creating tremendous social, economic, and political changes worldwide. Social distancing, sudden changes in daily routines, spending long periods at home, and limitations of social activities have had significant psychosocial impacts on people [4]. Anxiety, fear over personal health or the health of loved 
ones, and symptoms of depression or post-traumatic stress disorder have been shown to be typical reactions to the global pandemic [5, 6].

Female sexual function is influenced by multiple factors that affect the emotional and hormonal state of the individual [7]. Stress, change in daily routines, and fear of getting sick have adverse effects on sexual function through emotional and cognitive changes that distract the individual from sexual stimuli resulting in abnormal effects on genital and subjective arousal $[5,8]$.

Vaginismus is currently defined by the Diagnostic and Statistical Manual of Mental Disorders Fifth Edition (DSM5) as a subset of the genitopelvic pain/penetration disorder in which any form of vaginal penetration such as tampons, digits, vaginal dilators, gynecologic examinations, and intercourse is often painful or impossible [9]. Vaginismus has a psychological component manifested by fear and anxiety related to penetration and a physical component manifested by vaginal spasm $[10,11]$. Vaginal dilators of gradually increasing size may be used for the accomplishment of pelvic relaxation. After treatment, comfortable penetration is possible in the majority of women accompanied by an improvement in female sexual function [12].

Studies have evaluated the change in female sexual function during the COVID-19 pandemic in healthy reproductiveage women $[5,13]$. However, to our knowledge no studies have evaluated the sexual function of women who have been treated for genitopelvic pain/penetration disorder during the COVID-19 pandemic. In this study, we aim to evaluate the change in sexual function and frequency of sexual intercourse and dyspareunia in women who have been treated for genitopelvic pain/penetration disorder using vaginal dilators during the COVID-19 pandemic.

\section{Materials and methods}

To identify the effect of the COVID-19 pandemic on the sexual function of women treated for genitopelvic pain/ penetration disorder, the data obtained 3 months after comfortable penetration were compared with the data obtained during the peak phase of the pandemic (April-May 2020). Demographic data and the evaluation of female sexual function before the pandemic were obtained from the medical files of the women. All women who had been treated at our institution with the diagnosis of vaginismus as a subset of genitopelvic pain/penetration disorder and managed to achieve vaginal penetration between January 2018-October 2019 were included. Ethical approval was obtained from the institutional ethics committee, and verbal consent was obtained from all women to participate in the study. Women who were diagnosed with vulvar vestibulitis syndrome (vestibulodynia); who had a history of PID, TOA, and sexually transmitted diseases who were pregnant at the time of the study; and who were unwilling to fill out the questionnaires during a telephone interview were excluded.

The diagnosis of vaginismus as a subset of genitopelvic pain/penetration disorder was made based on history [14]. The relationship characteristics, gynecologic and menstrual history, medical and surgical history, drug usage, and presence of sexual and physical assault were questioned before treatment. Women who had a history of sexual assault were referred to psychiatric evaluation before treatment. Inspection of the genital area was performed to exclude other pathologies that could prevent penetration, and all patients underwent Q-tip application to the vestibular area to exclude vulvar vestibulitis syndrome (vestibulodynia). The stage of the vaginal spasm was determined using Lamont's staging system modified by Pacik and noted at the first session (Table 1) [14, 15]. Treatment with vaginal dilators was begun at the first session, starting from the smallest vaginal dilator $(2.5 \mathrm{~cm}$ circumference) promoting pelvic floor relaxation, and the dilators were gradually increased in size until reaching the biggest vaginal dilator that the patient could tolerate with a relaxed pelvis and without any pain or vaginal spasm. No local anesthetic or any other modality was used during vaginal dilator application. The patient was instructed how to use the vaginal dilator at home by herself and then with her partner every day. Sessions were performed every week, and vaginal dilators were
Table 1 Lamont grading system modified by Pacik

\begin{tabular}{|c|c|}
\hline $\begin{array}{l}\text { Lamont } \\
\text { Grade } 1\end{array}$ & Patient is able to relax for pelvic examination \\
\hline $\begin{array}{l}\text { Lamont } \\
\text { Grade } 2\end{array}$ & Patient is unable to relax for pelvic examination \\
\hline $\begin{array}{l}\text { Lamont } \\
\text { Grade } 3\end{array}$ & Buttocks lift off table. Early retreat. Toes curl upward \\
\hline $\begin{array}{l}\text { Lamont } \\
\text { Grade } 4\end{array}$ & Generalized retreat: buttocks lift up, thighs close, patient retreats \\
\hline Pacik Grade 5 & $\begin{array}{l}\text { Generalized retreat as in Lamont Grade } 4 \text { plus visceral reaction such as palpitations, } \\
\text { hyperventilation, sweating, severe trembling, uncontrollable shaking, hysteria, wanting to } \\
\text { jump off the table, a feeling of going unconscious, nausea, vomiting, and desire to attack the } \\
\text { doctor }\end{array}$ \\
\hline
\end{tabular}


gradually increased in size. When the largest vaginal dilator ( $3.5 \mathrm{~cm}$ circumference, $7 \mathrm{~cm}$ long) could be applied without pain and vaginal spasm, the couples were counseled regarding vaginal penetration, and sexual intercourse was advised. The couples were evaluated 3 weeks later to confirm the accomplishment of comfortable penetration.

All women underwent routine gynecologic examinations 2-3 months after initial sexual intercourse. Frequency of sexual intercourse was noted, and pain was evaluated using visual analogue scale. Sexual function was evaluated using the Female Sexual Function Index (FSFI) and female version of the Golombok-Rust Inventory of Sexual Satisfaction (GRISS), and depression was evaluated using the Beck Depression Inventory (BDI).

The FSFI is a 19-item questionnaire that measures female sexual function during the previous 4 weeks in six domains: desire, arousal, vaginal lubrication, orgasm, satisfaction, and pain [16]. All items are scored on an ascending scale except for the pain domain items, which are scored on a descending scale. Weighted subscale scores range from 1.2 to 6 . The total FSFI score ranges between 2 and 36, with higher scores indicating better sexual function. FSFI has been validated in Turkish [17].

The female version of the Golombok-Rust Inventory of Sexual Satisfaction (GRISS) is a 28 -item questionnaire for the assessment of sexual dysfunction in heterosexual couples [18]. The female version of the GRISS produces a total GRISS female score as well as subscales of anorgasmia, vaginismus, non-communication, infrequency, female avoidance, female non-sensuality, and female dissatisfaction. Higher scores indicate worse sexual function, and subscale scores $>$ 5 indicate sexual dysfunction. GRISS has been validated in Turkish [19].

The Beck Depression Inventory (BDI) is a 21-item selfreport rating inventory that measures characteristic attitudes and symptoms of depression [20]. The total score ranges from 0 to 63 . Scores between $0-9$ indicate no depression, 10-18 mild depression, 19-29 moderate depression, and 30-63 severe depression. BDI has been validated in Turkish [21].

A designated room was provided for the women for the completion of FSFI, GRISS, and BDI in a conventional paper and pencil format. All women completed the questionnaires alone.

During the pandemic, the presence and frequency of sexual intercourse, obstetric history, and preferred contraception method were questioned, and FSFI, GRISS, and BDI were filled out through telephone interview. Dyspareunia was evaluated using a visual analogue scale.

Primary outcomes of the study were the effects of the pandemic on FSFI, GRISS, and BDI scores. Secondary outcomes were the change in the frequency of sexual intercourse and change in the visual analogue scale for pain during sexual intercourse at the time of the COVID-19 pandemic.

\section{Statistical analysis}

Statistical package for the Social Sciences version 25 (SPSS) (IBM Corp.; Armonk, NY, USA) was used for statistical analysis. Data were expressed as mean \pm standard deviation. The Kolmogorov-Smirnov test was used to evaluate the distribution of normality. The paired sample t-test was used to compare the mean scores of the questionnaires, frequency of sexual intercourse, and visual analogue scales for pain during sexual intercourse post-treatment and during the pandemic. $P<0.05$ was considered statistically significant.

\section{Results}

One hundred thirty-five women were assessed for eligibility, and 21 women were excluded because of pregnancy or a diagnosis of vulvar vestibulitis syndrome (vestibulodynia). Thirty-seven women refused to participate; therefore, the total number of women included in the study was 77 during the peak phase of the pandemic period in the country (Fig. 1).

Mean age of the women was $30.2 \pm 6.1$ (19-52) years. Mean age of the partners was $33.0 \pm 6.0(24-55)$ years. Mean relationship duration was $60.9 \pm 75.2$ months (1-396 months). Fourteen (18.2\%) of the couples had arranged marriages. Demographic variables of the women are summarized in Table 2. Fifty-one (66.2\%) of the women and $46(59.7 \%)$ of the partners had graduated from university or had a higher degree. Four $(5.2 \%)$ of the women and three $(3.9 \%)$ of the partners were working as healthcare personnel. None of the couples had suffered from COVID-19 at the time of the study.

Fourteen (18.2\%) women had a history of depression/panic disorder, but only two (2.6\%) were using antidepressant drugs. Fifty-two (67.5\%) women had associated phobic reactions (acrophobia, achluphobia, claustrophobia, zoophobia). Nineteen women $(24.7 \%)$ had a history of traumatic family relationships, and $17(22.1 \%)$ had a history of sexual assault.

Sixty-five (84.4\%) of the women were able to touch their genital areas, and $66(85.7 \%)$ allowed their partners to touch their genital areas. Seventy-five $(97.4 \%)$ of the women performed sexual activities other than vaginal penetration. Nine women $(11.7 \%)$ had a history of anal penetration with their partners. Three women $(3.9 \%)$ had a history of pregnancy with petting and cesarean delivery. Thirty-five $(45.5 \%)$ of the women had a previous treatment history for vaginismus mainly by psychiatrists.

Thirty women (38.9\%) were Lamont Grade 3, 45 women (58.4\%) were Lamont Grade 4, and 2 women (2.6\%) were Pacik Grade 5. Mean duration of treatment was $3.5 \pm 2.6$ (1-12 months). Mean number of treatment sessions was 4.2 \pm 2.6 (1-15). No complications developed during the sessions.

All women could be examined at 2-3 months after initial sexual intercourse. None reported any complications. 
Fig. 1 Patients eligible for the study

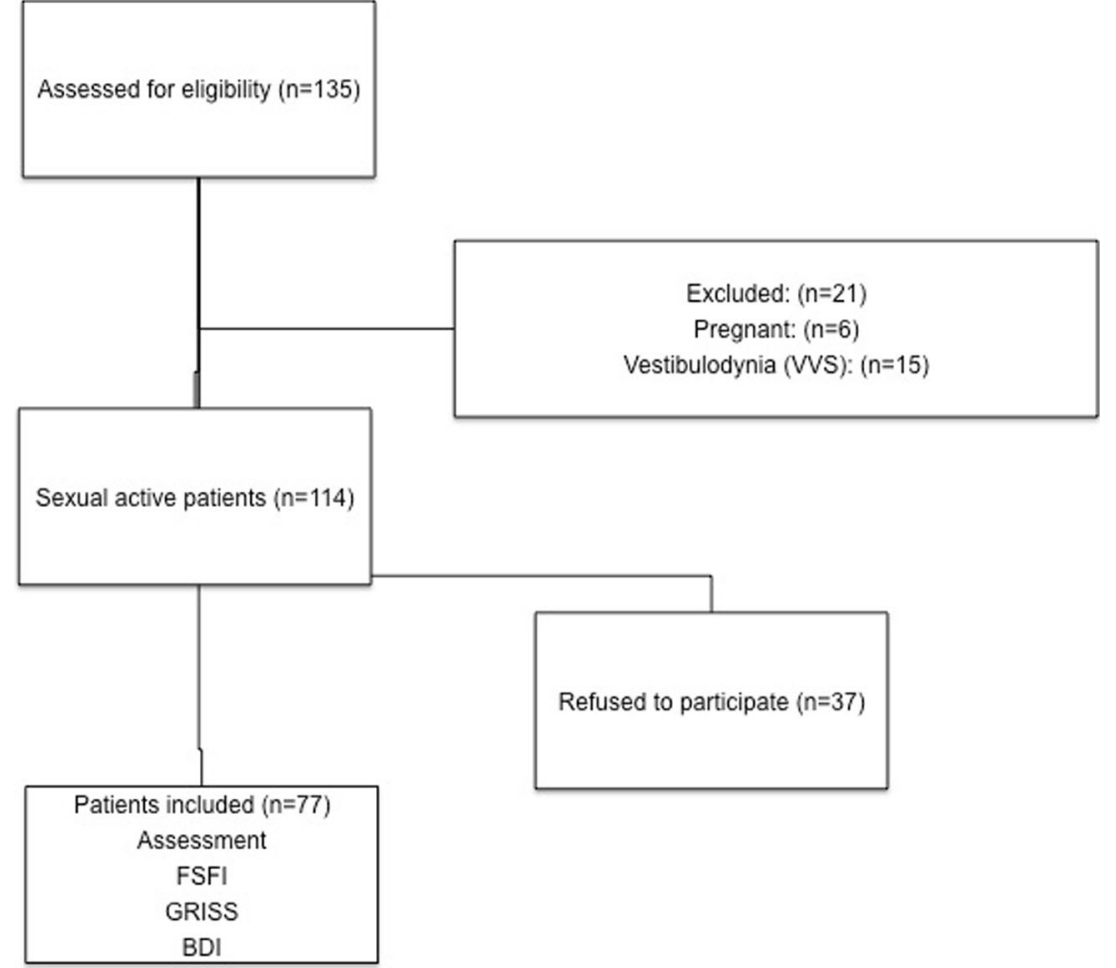

Contraception counseling was given, and the FSFI, GRISS, and BDI were filled out by the women. Mean frequency of sexual intercourse was $2.4 \pm 1.5$ per week, and mean visual analogue scale for pain was $6.2 \pm 2.9$. Three women (3.9\%) had uncomplicated pregnancies after treatment and delivered by cesarean section. None of the women were lactating at the time of the study.

Mean FSFI pain domain subscore and FSFI total score after treatment were $3.6 \pm 1.4(0-6)$ and $21.6 \pm 5.5(8.3-32.5)$, respectively. When the FSFI results during the pandemic were compared with the results after treatment, there were statistically significant improvements in the desire, arousal, orgasm, and pain domains and in the total score. Although lubrication and satisfaction domain scores were improved, the differences were not statistically significant. The results are summarized in Table 3.

The GRISS total scores after treatment and during the pandemic were $30.6 \pm 11.3(15-53)$ and $25.1 \pm 16.3$ (9-63), respectively. There was significant improvement in the total score and infrequency, noncommunication, avoidance, nonsensuality, and vaginismus domains. However, the scores significantly worsened in the dissatisfaction and anorgasmia domains. The results are summarized in Table 3.

The BDI score was $6.1 \pm 6.7(0-25)$ after treatment whereas the score was $12.3 \pm 11.0(0-37)$ during the pandemic. There was a significant worsening during the COVID-19 pandemic, which implied mild depression. The results are summarized in Table 3.

Mean frequency of sexual intercourse was $2.3 \pm 1.8$ per week, and visual analogue scale for pain was $2.7 \pm 2.8$ during the pandemic. The frequency of sexual intercourse did not change significantly; however, there was a significant decrease in the pain scores during the pandemic $(P=0.001)$.

\section{Discussion}

In our study, we showed that women treated for vaginismus (genitopelvic pain/penetration disorder) using vaginal dilators sustained their sexual function during the pandemic, and none developed secondary genitopelvic pain/penetration disorder. Although depression scores worsened during the pandemic, the frequency of sexual intercourse was not affected, and the pain scores and the total FSFI scores improved. However, the FSFI satisfaction and lubrication subscales improved less than the other domains. Improvement in pain may be associated with the improvement in other domains and the total FSFI score. The GRISS total score improved, but the dissatisfaction and anorgasmia domains actually worsened during the pandemic. In our study, women had higher BDI scores during the pandemic, which could be attributed to the psychological impact of the pandemic such as fear of catching the disease and anxiety about social distancing measures and lockdowns. Although the frequency of intercourse remained the same and the visual analogue scale for pain decreased, the quality of sexual intercourse was worse during the pandemic as reflected by the GRISS dissatisfaction and anorgasmia subscales and FSFI lubrication and satisfaction subscales. Fear of catching the disease from the partners during sexual 
Table 2 Demographic variables of the women $(n=77)$

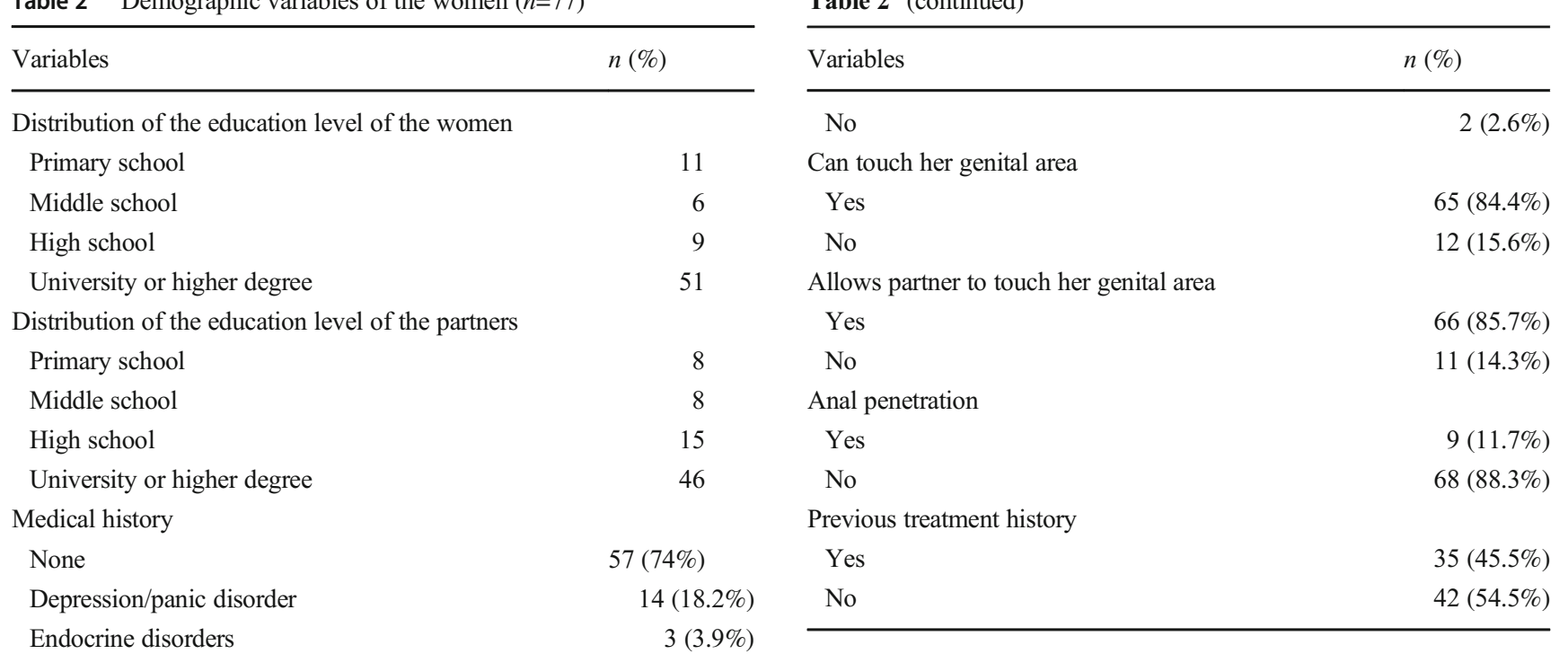

Polycystic ovary syndrome

Occupation

Housewife

Teacher

Healthcare (nurse, physiotherapist, veterinarian)

Accountant/finance/business worker

Government worker

Artist/archeologist

Engineer

Student

Partner's occupation

Unemployed

Teacher

Healthcare (dentist, physiotherapist, veterinarian )

Engineer/architect

Accountant/finance/business worker

Technician/government worker

Art/tourism

Medical treatment

Antidepressants

Oral contraceptives

Smoking

Yes

No

Associated phobic reactions

Yes

No

History of family trauma

Yes

No

History of sexual assault

Yes

No

Sexual activity without vaginal penetration

Yes
Table 2 (continued)

intercourse by kissing or intimate contact might have an adverse effect on sexual function.

Sexual activity is associated with mental and psychological health [22]. High levels of chronic stress result in a decrease in sexual desire [7]. In addition, it has been shown during the initial phase of the COVID-19 outbreak that female gender, student status, and specific physical symptoms were associated with a greater psychological impact and higher levels of stress, anxiety, and depression [23]. The presence of phobic reactions among our patients might have influenced their depressive symptoms and anxiety towards the pandemic [24]. Long-term mental symptoms such as panic, anxiety, and distress associated with the pandemic have been collectively termed 'coronaphobia' and are observed more among people who are predisposed to anxiety and have pre-existing mental health problems [25]. In women with genitopelvic pain/penetration disorder, anxiety and depression have been associated with greater pain intensity and sexual dysfunction, so that a highly stressful situation such as a lockdown could result in worsening sexual function [26].

Results regarding the effect of the pandemic on female sexual function are contradictory. Schiavi et al. evaluated the sexual function and quality of life during social distancing measures in 89 Italian reproductive age women [5]. Mean sexual intercourse/month, FSFI total score, and SF-36 decreased significantly, whereas the FSDS score increased significantly during the pandemic. The authors suggested that despite the longer cohabitation time, women who lived with their partners had reduced sexual activity. On the other hand, Yuksel and Ozgor evaluated the effect of COVID-19 pandemic on female sexual behavior in women in Turkey [13]. The authors found that frequency of sexual intercourse significantly increased, but the FSFI scores worsened during the pandemic. In addition, couple dynamics may be influenced by the pandemic and may have an adverse impact on the marital life and sexual function [27]. Significant time spent in lockdown 
Table 3 Results of the FSFI, GRISS, and BDI post-treatment and during the COVID-19 pandemic

\begin{tabular}{lccc}
\hline & Post-treatment $(n=77)$ & Pandemic $(n=77)$ & $P$ values \\
\hline FSFI & & & \\
Desire & $3.6 \pm 1.6(1.2-6)$ & $3.9 \pm 1.2(1.2-6)$ & 0.035 \\
Arousal & $3.2 \pm 1.2(0-6)$ & $3.9 \pm 1.7(0-6)$ & 0.002 \\
Lubrication & $4.1 \pm 1.3(1.2-6)$ & $4.4 \pm 1.7(0-6)$ & 0.153 \\
Orgasm & $3.1 \pm 1.5(0-5.6)$ & $3.6 \pm 1.8(0-6)$ & 0.033 \\
Satisfaction & $3.9 \pm 1.2(1.6-6)$ & $4.1 \pm 1.3(0.8-6)$ & 0.225 \\
Pain & $3.6 \pm 1.4(0-6)$ & $4.3 \pm 2.1(0-6)$ & 0.004 \\
Total Score & $21.6 \pm 5.5(8.3-32.5)$ & $24.2 \pm 8.3(2.3-35.7)$ & 0.010 \\
Golombok-Rust Inventory of Sexual Satisfaction (GRISS) & & \\
Infrequency & $4.6 \pm 1.8(1-9)$ & $3.7 \pm 2.6(1-8)$ & 0.09 \\
Non-communication & $3.9 \pm 1.9(1-8)$ & $2.9 \pm 1.7(0-8)$ & 0.04 \\
Dissatisfaction & $3.5 \pm 1.8(1-7)$ & $6.0 \pm 3.4(2-12)$ & 0.001 \\
Avoidance & $4.2 \pm 2.1(1-8)$ & $1.8 \pm 2.2(0-7)$ & 0.009 \\
Non-sensuality & $4.7 \pm 2.6(1-9)$ & $2.7 \pm 2.2(0-8)$ & 0.028 \\
Anorgasmia & $3.7 \pm 1.3(2-6)$ & $5.4 \pm 2.7(2-11)$ & 0.022 \\
Vaginismus & $6.1 \pm 2.1(2-9)$ & $3.0 \pm 4.5(0-14)$ & 0.028 \\
Total score & $30.6 \pm 11.3(15-53)$ & $25.1 \pm 16.3(9-63)$ & 0.089 \\
Beck Depression Inventory Score & $6.1 \pm 6.7(0-25)$ & $12.3 \pm 11.0(0-37)$ & 0.020 \\
\hline
\end{tabular}

* Paired sample t-test was used for statistical analysis may lead to anxiety, depression, and fear leading to orgasmic dysfunction and anorgasmia in both men and women [26]. In our study, the increase in the GRISS dissatisfaction and anorgasmia subscales could also be related to the change in couple dynamics during the pandemic.

Many protocols exist regarding vaginal dilation recommendations to overcome vaginismus [12]. Teaching women how to use vaginal dilators in the outpatient clinic decreases women's fears about harming themselves, and women learn how to relax their pelvic floor during vaginal dilation by verbal feedback. It is also helpful for the couple when the partner assists with the vaginal dilators to help transition to intercourse physically and psychologically [12]. Aslan et al. compared dilator use and finger use among women suffering from vaginismus and suggested that dilator use was more successful regarding treatment continuity and led to more improvement in sexual function [28]. Pacik et al. followed up 241 women with vaginismus and reported that $171(71 \%)$ achieved pain-free intercourse at a mean of 5.1 weeks after multimodal treatment including intravaginal botulinum toxin and bupivacaine injections and progressive dilation [12]. There was a significant improvement in the total FSFI score after treatment. The authors suggested that women with severe vaginismus had a high rate of recurrence if they stopped dilating for 6 months. In our study, none of the women had recurrent vaginismus during the pandemic and continued comfortable penetration with a decrease in pain scores, and this might be a reason for improvement in FSFI scores despite the pandemic.

In China, some precautionary measures including psychological support lead to a lower level of stress, anxiety, and depression and a better psychological outcome [6]. Psychological support for the women treated for genitopelvic pain/penetration disorder during the pandemic could possibly decrease the level of anxiety, stress, and depression in these women and improve couple dynamics and sexual function. Changes that have occurred in health care in many countries had an overall negative impact on sexual and reproductive health [29]. Availability and accessibility of good quality of services for women are critical in the response to the pandemic [30].

The present study has several strengths. First, we used an adequate sample size of women treated for genitopelvic pain/ penetration disorder. Second, we were able to compare the sexual function and quality of life before and during the pandemic. Third, we used well-validated measures of sexual and mental health. Main limitations of our study are that not all women treated for genitopelvic pain/penetration disorder agreed to participate in the study, women included in the study were surveyed through telephone interview, and the sexual function of their partners was not evaluated.

In conclusion, the present study demonstrated that frequency of sexual intercourse did not change among women treated for vaginismus (genitopelvic pain/penetration disorder), and most of the sexual function scores including pain improved during the pandemic despite the increase in stress and depression scores. However, dissatisfaction and anorgasmia subscales worsened, and FSFI satisfaction and lubrication subscales did not improve as much, indicating adverse effects on sexual function. Future studies could evaluate the effect of psychological support in these women to cope with stress, anxiety, and depression and improve their sexual function. 
Author's contribution FGU: Project development, data collection, analysis, manuscript writing. CY: Project development, data analysis, manuscript writing. MAT: Project development, data collection, data analysis, manuscript writing. IE: Data collection, data analysis. C.I.: Project development, data collection, data analysis. OD: Project development, manuscript editing. SEA: Project development, supervision, data analysis, manuscript editing.

\section{Declarations}

Conflicts of interest None.

\section{References}

1. Cheng VC, Wong SC, To KK, Ho PL, Yuen KY. Preparedness and proactiveinfection control measures against the emerging novel coronavirus in China. J Hops Infect. 2020;104:254-5.

2. Ugurlucan M, Yildiz Y, Oztas DM, Coban S, Beyaz MO, Sari G, Ulukan MO, Karakaya A, Vatansever B, Erkanli K, Meric M, Unal O, Demirkol D, Yozgat Y, Saritas T, Erdem A, Akdeniz C, Turkoglu H. Congenital cardiac interventions during the peak phase of COVID-19 pandemics in the country in a pandemics hospital in Istanbul. Cardiol Young. 2020;24:1-9. https://doi.org/10.1017/ S1047951120002000.

3. Türkiye Günlük Koronavirüs Tablosu. https://covid19.saglik.gov. tr/TR-66122/genel-koronavirus-tablosu.html. Retrieved 22 November 2020

4. Wang C, Pan R, Wan X, et al. Immediate psychological responses and associated factors during the initial stage of the 2019 Coronavirus disease (COVID-19) epidemic among the general population in China. Int J Environ Res Public Health. 2020;17:1729.

5. Schiavi MC, Spina V, Zullo MA, et al. Love in the Time of COVID-19: sexual function and quality of life analysis during the social distancing measures in a group of Italian reproductive-age women. J Sex Med. 2020;17:1407-13.

6. Cao W, Fang Z, Hou G, Han M, Xu X, Dong J, Zheng J. The psychological impact of the COVID-19 epidemic on college students in China. Psychiatry Res. 2020;287:112934.

7. Hamilton LD, Meston CM. Chronic stress and sexual function in women. Sex Med. 2013;10(10):2443-54.

8. Guo L, Chen YX, Hu YT, Wu XY, He Y, Wu JL, Huang ML, Mason M, Bao AM. Sex hormones affect acute and chronic stress responses in sexually dimorphic patterns: consequences for depression models. Psychoneuroendocrinology. 2018;95:34-42.

9. American Psychiatric Association. Diagnostic and statistical manual of mental disorders. 5th ed. Washington, DC: American Psychiatric Association; 2013.

10. Rosenbaum TY, Owens A. The role of pelvic floor physical therapy in the treatment of pelvic and genital pain-related sexual dysfunction. J Sex Med. 2008;5(3):513-23.

11. Pacik PT. Vaginismus: review of current concepts and treatment using Botox injections, bupivacaine injections, and progressive dilation with the patient under anesthesia. Aesthetic Plast Surg. 2011;35:1160-4.

12. Pacik PT, Geletta S. Vaginismus treatment: clinical trials follow-up of 241 patients. Sex Med. 2017;5(2):e114-23.

13. Yuksel B, Ozgor F. Effect of the COVID-19 pandemic on female sexual behaviour. Int J Gynecol Obstet. 2020;150:98-102.
14. Pacik PT. Understanding and treating vaginismus: a multimodal approach. Int Urogynecol J. 2014;25:1613-20.

15. Lamont JA. Vaginismus. Am J Obstet Gynecol. 1978;131:633-6.

16. Rosen R, Brown C, Heiman J, Leiblum S, Meston C, Shabsigh R, et al. The Female Sexual Function Index (FSFI): a multidimensional self-report instrument for the assessment of female sexual function. J Sex Marital Ther. 2000;26:191-208.

17. Oksuz E, Malhan S. Kadin CinselFonksiyonIndeksi: Turkce uyarlamasinin gecerlilik ve guvenilirlik analizi. Reliability and validity of the Female Sexual Function Index in a Turkish population. Syndrome. 2005;17(7):54-60.

18. Rust J, Golombok S. The GRISS: a psychometric instrument for the assessment of sexual dysfunction. Archives of Sexual Behavior. 1986;15(2):157-65.

19. Tuğrul C, Öztan N, Kabakçı E. Golombok-Rust Cinsel Doyum Ölçeği'nin standardizasyon çalıșması. Türk Psikiyatri Dergisi. 1993;4(2):83-8.

20. Beck AT, Ward CH, Mendelson M, Mock J, Erbaugh J. An inventory for measuring depression. Arch Gen Psychiatry. 1961;4:56171.

21. Hisli N. Beck Depresyon Envanterinin Üniversite Öğrencileri İçin Geçerliği ve Güvenirliği. Psikoloji Dergisi. 1989;7:3-13.

22. Sansone A, Mollaioli D, Ciocca G, Limoncin E, Colonnello E, Vena W, Jannini EA. Addressing male sexual and reproductive health in the wake of Covid-19 outbreak. J Endocrinol Invest. 2020. https://doi.org/10.1007/s40618-020-01350-1.

23. Duan L, Zhu G. Psychological interventions for people affected by the COVID-19 epidemic. Lancet Psychiatry. 2020;7:300-2.

24. Fond G, Franc N. Treating specific childhood phobia in a single session? A systematic review of the literature. Encephale. 2013;39(2):109-14.

25. COVID-19's Psychological Impact Gets a Name - Medscape - Sep 29, 2020. https://www.medscape.com/viewarticle/938253\#vp_2.

26. Pennanen-Iire C, Prereira-Lourenço M, Padoa A, Ribeirinho A, Samico A, Gressler M, Jatoi N-A, Mehrad M, Girard A. Sexual health implications of COVID-19 pandemic. Sex Med Rev. 2020. https://doi.org/10.1016/j.sxmr.2020.10.004.

27. Mollaioli D, Ciocca G, Limoncin E, di Sante S, Gravina GL, Carosa E, Lenzi A, Jannini EAF. Lifestyles and sexuality in men and women: the gender perspective in sexual medicine. Reprod Biol Endocrinol. 2020;17:10.

28. Aslan M, Yavuzkir S, Baykara S. Is dilator use more effective than finger use in exposure therapy in vaginismus treatment. J Sex Marital Ther. 2020. https://doi.org/10.1080/0092623X.2020. 1716907.

29. Endler M, Al-Haidari T, Benedetto C, Chowdhury S, Christilaw J, El Kak F, Galimberti D, Garcia-Moreno C, Gutierrez M, Ibrahim S, Kumari S, McNicholas C, Mostajo Flores D, Muganda J, RamirezNegrin A, Senanayake H, Sohail R, Temmerman M, GemzellDanielsson K. How the Covid-19 pandemic is impacting sexual and reproductive health and rights and response: results from a global survey of providers, researchers, and policy makers. Acta Obstet Gynecol Scand. 2020. https://doi.org/10.1111/aogs.14043.

30. Hussein Julia. COVID-19: what implications for sexual and reproductive health and rights globally? Sex Reprod Health Matters. 2020;28(1):1746065. https://doi.org/10.1080/26410397.2020. 1746065 .

Publisher's note Springer Nature remains neutral with regard to jurisdictional claims in published maps and institutional affiliations. 